\title{
Fabrication and Characterization of Nickel Chloride Doped PMMA Films
}

\author{
Wasan A. Al-Taa'y, ${ }^{1}$ Saad F. Oboudi, ${ }^{2}$ Emad Yousif, ${ }^{3}$ Mohammed Abdul Nabi, ${ }^{1}$ \\ Rahimi M. Yusop, ${ }^{4}$ and Darfizzi Derawi ${ }^{4}$ \\ ${ }^{1}$ Department of Physics, College of Science, Al-Nahrain University, Baghdad, Iraq \\ ${ }^{2}$ Department of Physics, College of Science, Baghdad University, Baghdad, Iraq \\ ${ }^{3}$ Department of Chemistry, College of Science, Al-Nahrain University, Baghdad, Iraq \\ ${ }^{4}$ School of Chemical Sciences and Food Technology, Faculty of Science and Technology, Universiti Kebangsaan Malaysia, \\ 43600 Bangi, Selangor, Malaysia
}

Correspondence should be addressed to Rahimi M. Yusop; rahimi@ukm.my

Received 19 August 2014; Revised 29 November 2014; Accepted 30 November 2014

Academic Editor: Weihua Tang

Copyright ( 2015 Wasan A. Al-Taa'y et al. This is an open access article distributed under the Creative Commons Attribution License, which permits unrestricted use, distribution, and reproduction in any medium, provided the original work is properly cited.

Films of PMMA and PMMA doped with $\mathrm{NiCl}_{2}$ with different contents were prepared using the casting technique. The optical properties of all films were investigated using spectrophotometric measurements of absorbance and transmittance in the wavelength range $200-800 \mathrm{~nm}$. The change of the calculated values of the optical energy gaps with increasing $\mathrm{NiCl}_{2}$ content has been interpreted in terms of the structural modifications of the PMMA matrix. The optical energy gap decreased from 3.6 to $3.05 \mathrm{eV}$ with increasing the $\mathrm{NiCl}_{2}$ concentration to $0.4 \%$. The effect of doping on the optical constants of films such as refractive index, extinction coefficient, real and imaginary parts of dielectric constant, optical conductivity, and skin depth has been reported. All these constants were increased with increasing $\mathrm{NiCl}_{2}$ concentration with the exception of skin depth which is different result.

\section{Introduction}

Optical properties of polymer films are very important for many technological applications [1], ranging from protective coatings to paintings, microelectronic, semiconductors, and optoelectronic devices depending on the reflectance and transmittance properties of the films during their preparation $[2,3]$. PMMA as a polymeric waveguide has attracted much attention for use as optical components and in optoelectronics devices due to their low cost and volume productivity. Recently, some researchers reported optical components such as an optical switch, a coupler, a splitter, and a transceiver $[4,5]$.

PMMA is considered as an excellent host material for doping due to their good transparency (the transmission for visible light is very high), resistivity, mechanical strength, and optical homogeneity which can play an important role in building up advanced optical materials [6]. It is one of the earliest and best known polymers. PMMA was seen as a replacement for glass in a variety of applications and is currently used extensively in glazing applications. The material is one of the hardest polymers and is rigid, glass-clear with glossy finish and good weather resistance [7].

Owing to the influence of doping on the properties of polymeric materials, the controlled preparation of PMMA of different doping materials and concentrations is always the researcher's purpose; these doping processes cause a remarkable change in their properties $[8,9]$. The present work is a part of a systematic study of the effect of doping of $\mathrm{NiCl}_{2}$ on PMMA on improving their physical properties. Therefore, we study the effect of the doping level $(W)$ using both the optical absorption measurements and the determination of the optical constants and energy gap. The accurate determination of the optical constants of these materials is important, in order not only to know the basic mechanisms underlying these 
phenomena but also to exploit and develop their interesting technological applications.

\section{Experimental Details}

Films of poly(methyl methacrylate) PMMA doped with different weight concentration of nickel chloride $\left(\mathrm{NiCl}_{2}\right)$ salt $(0.1,0.2,0.3$, and $0.4 \%)$ have been prepared by the dispersed polymer and $\mathrm{NiCl}_{2}$ dissolve in $100 \mathrm{~mL}$ chloroform with stirring the solution, using a magnetic stirrer for about $30 \mathrm{~min}$ at room temperature for complete dissolving. Different polymer solutions (volumetric solutions) were casted as a layer, dried at room temperature for 24 hours. Layer thickness was measured using indicating micrometer $0.25 \mu \mathrm{m}$; all layers were found to be in the range of $20 \pm 1 \mu \mathrm{m}$; these layers were clear, transparent, and free from any noticeable defect showing light bluish color.

Optical transmittance and absorbance were recorded in the wavelength range of $200-800 \mathrm{~nm}$ using computerized UV-VIS spectrophotometer (Shimadzu UV-1601 PC). Optical transmittance and absorbance were reported in order to study the effect of doping on the parameters under investigation.

\section{Results and Discussion}

The optical properties of films by means of optical absorption in the UV-VIS region of 200-800 nm have been investigated. Figure 1 shows the dependence of absorbance $(A)$ on wavelength $(\lambda)$ of all films before and after being doped by $\mathrm{NiCl}_{2}$ salt with different concentrations $(0.1,0.2,0.3$, and $0.4 \%)$. It is observed that in the visible region all films have very low transparent; then absorbance is rapidly decreased with increasing wavelength. This behavior may be attributed to perfection and stoichiometry of the films. Also it can be observed from the figure that the absorbance increased with increasing the doping concentration of $\mathrm{NiCl}_{2}$ to $0.4 \%$; this result agrees with the previous work [10]. It has been observed that the absorption peaks appear at wavelengths 240, 242, 248, 249 , and $251 \mathrm{~nm}$ as the concentration of dopant varies from 0 to $0.4 \mathrm{~mol} / \mathrm{L}$ in PMMA matrix, respectively. The shifting occurring in the spectra may be due to the polarity of solvent used in the synthesis or may be due to the dispersion of rare earth oxide particles in the PMMA matrix [11].

From the transmittance $(T)$ data and according to Tauc [12] relation, the most satisfactory representation is obtained by plotting the quantity $(\alpha h v)^{2}$ as a function of $(h v)$. The plot of $(\alpha h v)^{2}$ versus $h v$ for different dopant percentage in polymer samples is shown in Figure 2. The observed behavior suggests allowed direct transition for amorphous material [13]. The values of optical energy gap $E_{\text {opt }}$ obtained from the extrapolation of the linear region are found to be decrease for all samples 3.6, 3.5, 3.29, 3.19, and $3.05 \mathrm{eV}$ with increasing the doping percentage of $\mathrm{NiCl}_{2} 0.1,0.2,0.3$, and $0.4 \%$, respectively. The decrease in $E_{\text {opt }}$ with increasing $\mathrm{NiCl}_{2}$ concentration can be understood by considering the mobility gap variation in the doped polymer [14]. The figure shows a linear dependence for pure PMMA in one region representing one optical absorption edge as mentioned before in previous work

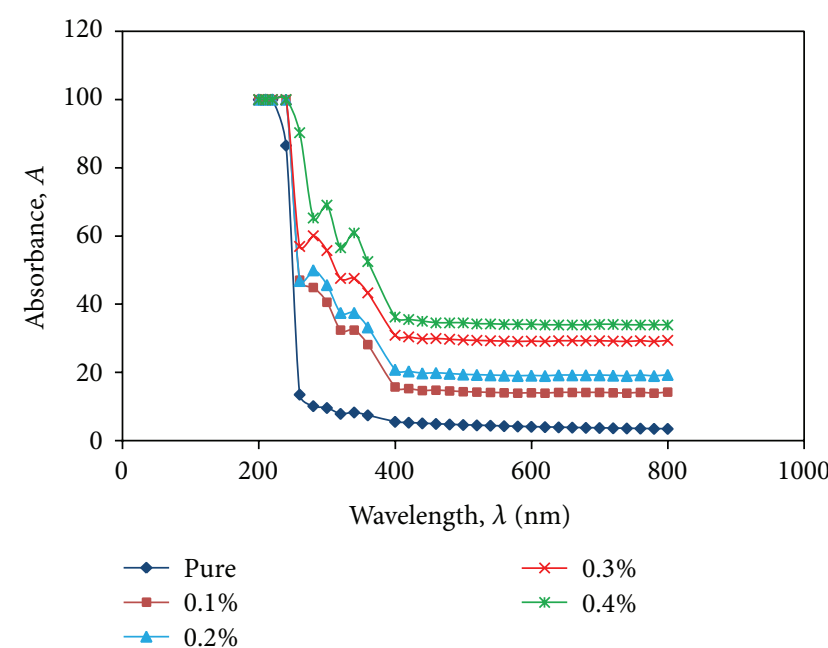

FIGURE 1: The variation of absorbance with wavelength for pure and doped PMMA films.

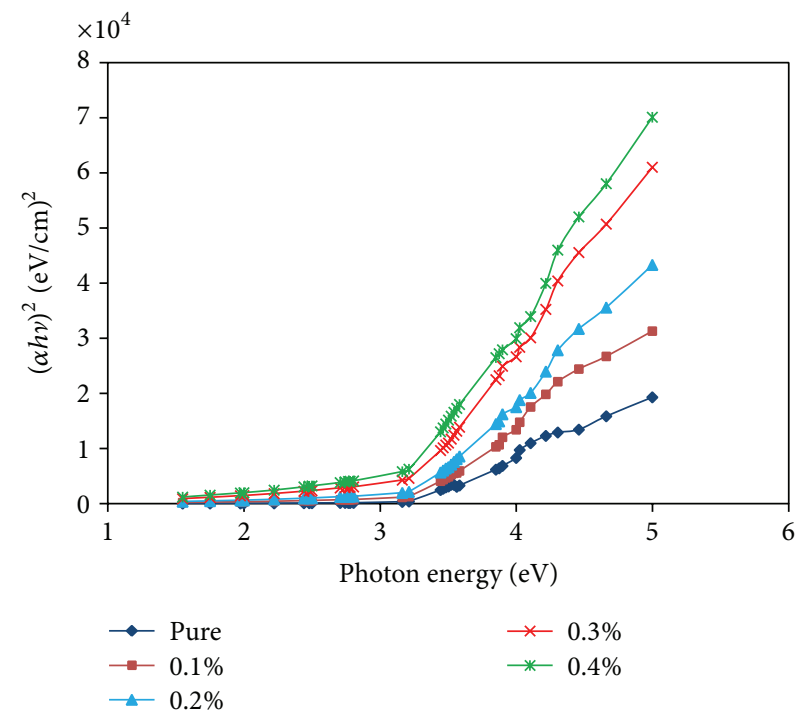

FIGURE 2: The $(\alpha h v)^{2}$ versus photon energy for pure and doped PMMA films.

$[9,15-17]$. The value obtained in this work is close to others previously reported for the allowed direct transition.

The refractive index $(n)$ is an important parameter for optical materials and applications. Thus, it is important to determine optical constants of the films. The refractive index of the films was determined from the following relation [18]:

$$
n=\left(\frac{1+R}{1-R}\right)+\sqrt{\frac{4 R}{(1-R)^{2}}-K^{2}},
$$

where $R$ represent the reflectance and $k$ is the extinction coefficient $(k=\alpha \lambda / 4 \pi)$ where $\alpha$ is the absorption coefficient. The $n$ and $k$ values of dependence of wavelength are shown in Figures 3 and 4, respectively, for all samples before and after being doped. As seen in these figures, the $n$ and $k$ values increase with increasing the doping concentration of 


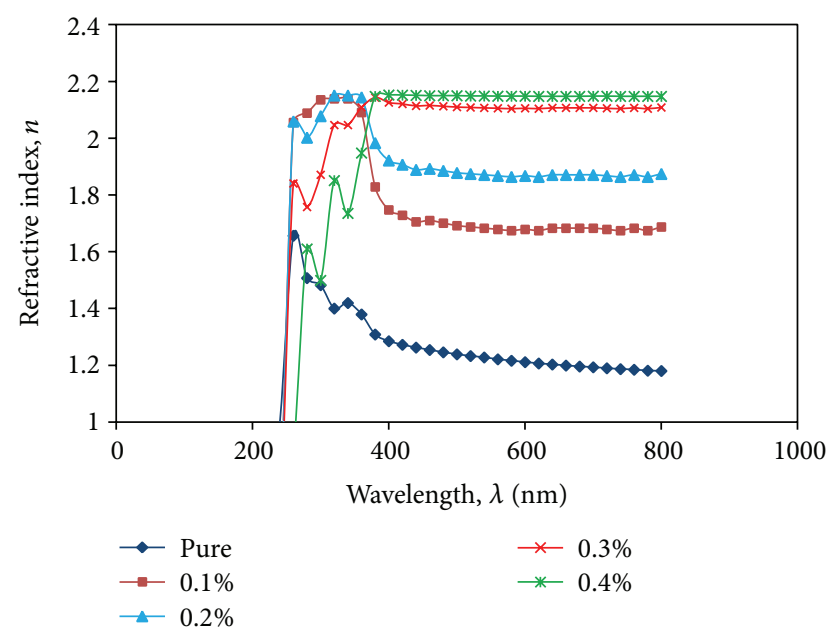

FIGURE 3: The variation of refractive index with wavelength for pure and doped PMMA films.

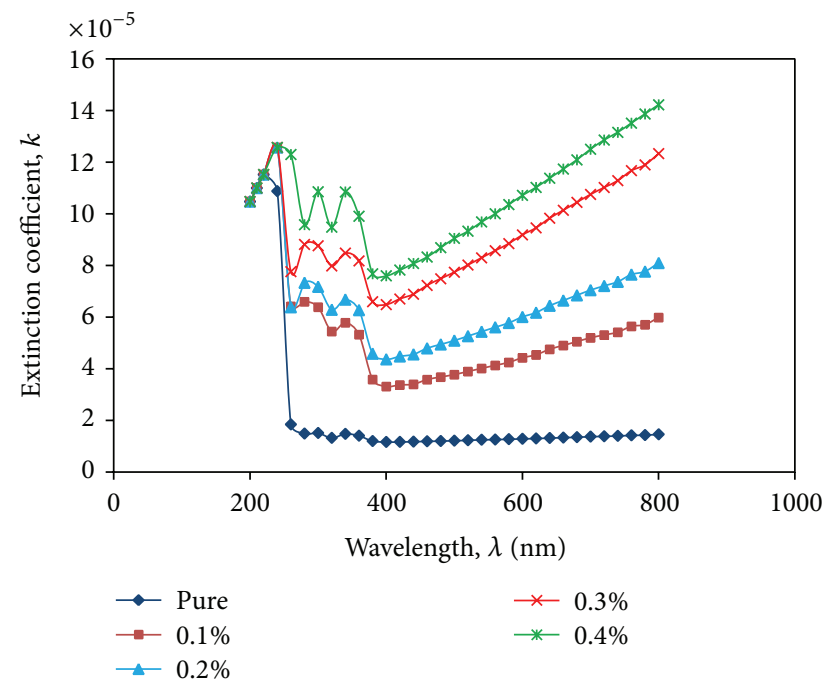

FIGURE 4: The extinction coefficient versus wavelength for pure and doped PMMA films.

$\mathrm{NiCl}_{2}$; this result agrees with the previous work [19]. Such behavior corresponds to the density of absorbing centers such as impurities absorption, excitation transition, and other defects in the crystal lattice dependent on the conditions of sample preparation.

The dielectric constant is defined as $\varepsilon(\omega)=\varepsilon_{1}(\omega)+i \varepsilon_{2}(\omega)$; real $\left(\varepsilon_{1}\right)$ and imaginary $\left(\varepsilon_{2}\right)$ parts of the dielectric constant are related to the $n$ and $k$ values. The $\varepsilon_{1}$ and $\varepsilon_{2}$ values were calculated using the following formulas [20]

$$
\begin{gathered}
\varepsilon_{1}=n^{2}-k^{2}, \\
\varepsilon_{2}=2 n k .
\end{gathered}
$$

The $\varepsilon_{1}$ and $\varepsilon_{2}$ values of dependence of wavelength are, respectively, shown in Figures 5 and 6 for pure and doped films. The $\varepsilon_{1}$ values are higher than $\varepsilon_{2}$ values. It is seen that the $\varepsilon_{1}$ and $\varepsilon_{2}$ values increase with increasing wavelength and with

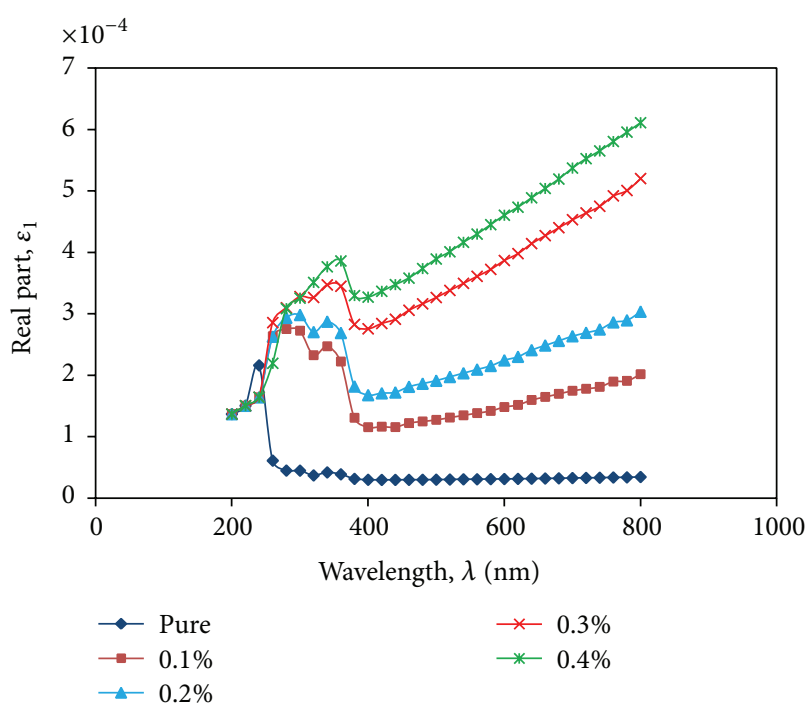

FIGURE 5: The variation of real part of dielectric constant with wavelength for pure and doped PMMA films.

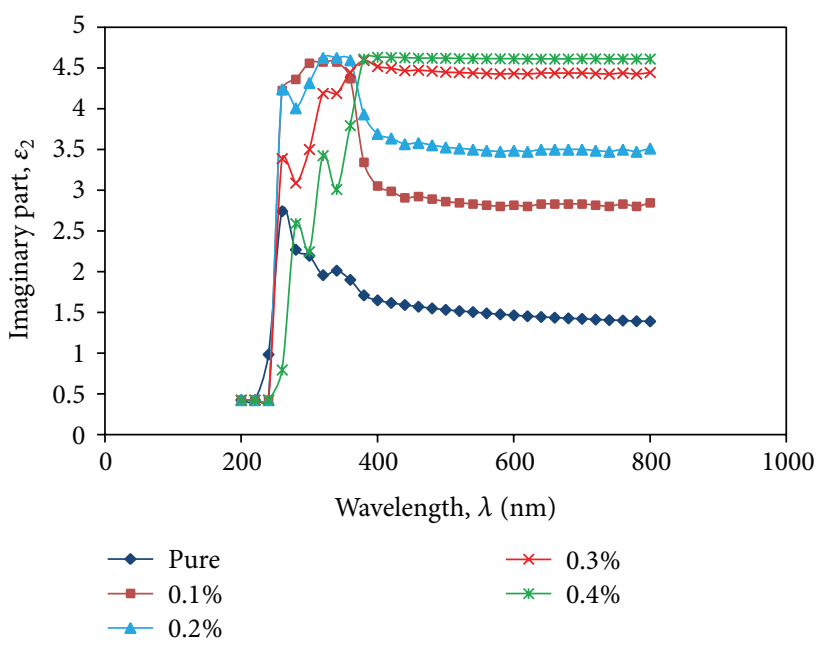

FIGURE 6: The variation of imaginary part of dielectric constant with wavelength for pure and doped PMMA films.

the doping concentration of $\mathrm{NiCl}_{2}$. The values of dielectric constant at $400 \mathrm{~nm}$ for $0,0.1,0.2,0.3$, and $0.4 \% \mathrm{NiCl}_{2}$ content were $1.75,3.08,3.71,4.45$, and 4.60 , respectively, for real part and $0.000035,0.000123,0.000177,0.000285$, and 0.000342 , respectively, for imaginary part. Moreover, this increase by the variation of $\varepsilon_{1}$ mainly depends on $n^{2}$ because of small values of $k^{2}$ while $\varepsilon_{2}$ mainly depends on $k$ value which is related to the variation of absorption coefficients [21].

The optical conductivity $(\sigma)$ was calculated using the following relation [22]:

$$
\sigma=\frac{\alpha n c}{4 \pi}
$$

where $c$ is the velocity of light.

Figure 7 shows the variation of optical conductivity with the wavelength. It was observed that the optical conductivity 


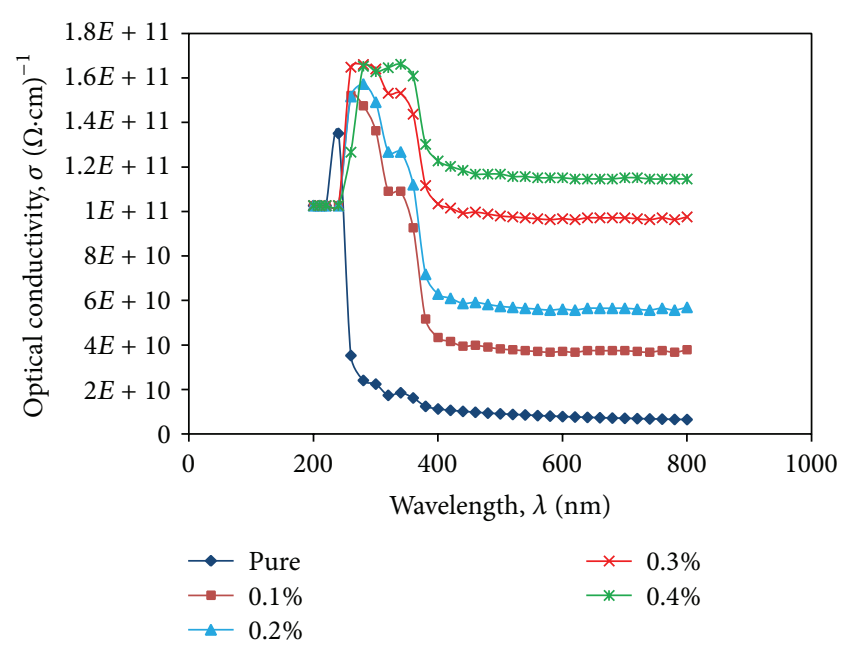

FIGURE 7: The optical conductivity versus wavelength for pure and doped PMMA films.

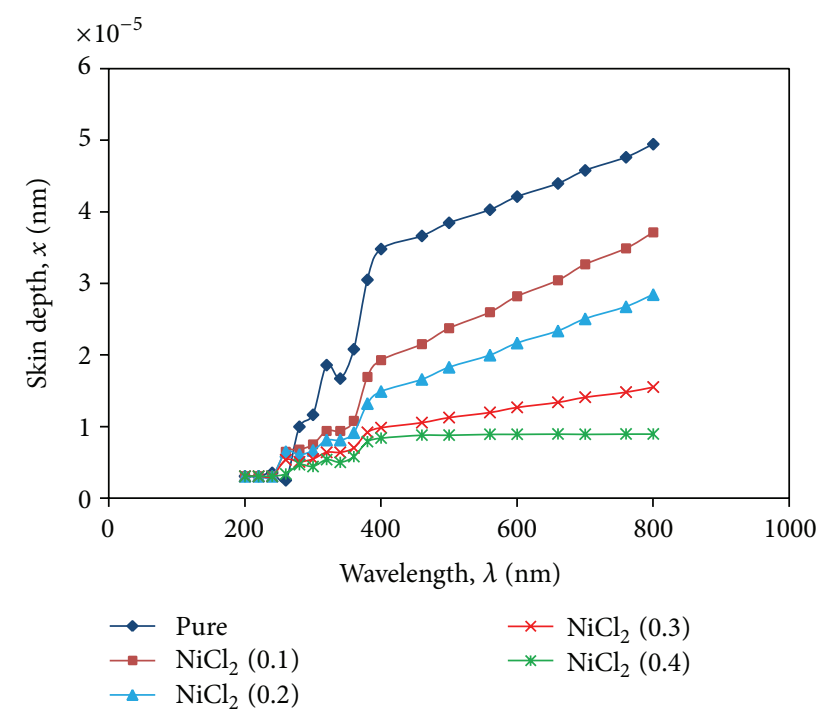

FIGURE 8: The skin depth versus wavelength for pure and doped PMMA films.

increases as the doping percentage of $\mathrm{NiCl}_{2}$ in the PMMA increases to $0.4 \%$. It can be noticed from the figure that the optical conductivity for all films increased in the low wavelengths region and decreased in the high wavelength region; this decrease is due to the low absorbance of the films in that region.

The skin depth $(x)$ could be calculated using the following relation [23]:

$$
x=\frac{\lambda}{2 \pi k} .
$$

Figure 8 shows the variation of skin depth as a function of wavelength for all films. It is clear from the figure that the skin depth increases as the wavelength increases; this behavior could be seen for all samples, but the skin depth decreases as the doping concentration increases, so the skin depth is a transmittance related.

\section{Conclusion}

PMMA and $\mathrm{NiCl}_{2}$ doped PMMA films were prepared by using casting technique. Both pure and doped samples were characterized. Results indicate that the optical band gap and the optical parameters are strongly dependent on doping with $\mathrm{NiCl}_{2}$. The optical band gap decreased from 3.6 to $3.05 \mathrm{eV}$ with increasing the doping concentration to $0.4 \%$. The refractive index, extinction coefficient, the real and imaginary parts of dielectric constant, and the optical conductivity were calculated and they are tending to increase with increasing the doping concentration of $\mathrm{NiCl}_{2}$; on the other hand, the skin depth decreases with increasing the doping concentration. These present observations can help improve the understanding of the optical parameters of $\mathrm{NiCl}_{2}$ films.

\section{Conflict of Interests}

The authors declare that there is no conflict of interests regarding the publication of this paper.

\section{Acknowledgments}

The authors thank the Al-Nahrain University and Universiti Kebangsaan Malaysia for the funding (Codes AP-2011 17, DPP-2013-054, UKM-MI-OUP-2011, AP-2012-017, and DLP 2013-002).

\section{References}

[1] A. Tawansi, H. M. Zidan, Y. M. Moustafa, and A. H. Eldumiaty, "Optical and electrical properties of $\mathrm{NiCl}_{2}$ filled PVC films," Physica Scripta, vol. 55, no. 2, pp. 243-246, 1997.

[2] R. Oslanec, A. C. Costa, R. J. Composto, and P. Vlcek, "Effect of block copolymer adsorption on thin film dewetting kinetics," Macromolecules, vol. 33, no. 15, pp. 5505-5512, 2000.

[3] G. Reiter, "Dewetting as a probe of polymer mobility in thin films," Macromolecules, vol. 27, no. 11, pp. 3046-3052, 1994.

[4] Y. S. Heo, S. Chung, K. Cho, C. Chung, D.-C. Han, and J. K. Chang, "Effects of peak anomalies with the hydrophilic or hydrophobic properties of reservoirs during serial injection on a capillary electrophoresis microchip," Journal of Chromatography A, vol. 1013, no. 1-2, pp. 111-122, 2003.

[5] Z. Chen, Y. Gao, J. Lin, R. Su, and Y. Xie, "Vacuum-assisted thermal bonding of plastic capillary electrophoresis microchip imprinted with stainless steel template," Journal of Chromatography A, vol. 1038, no. 1-2, pp. 239-245, 2004.

[6] A. Tawansi, A. El-khodary, H. M. Zidan, and S. I. Badr, "The effect of $\mathrm{MnCl}_{2}$ filler on the optical window and the physical properties of PMMA films," Polymer Testing, vol. 21, no. 4, pp. 381-387, 2002.

[7] T.-L. Tsai, C.-C. Lin, G.-L. Guo, and T.-C. Chu, "Effects of microwave-assisted digestion on decomposition behavior of polymethyl methacrylate (PMMA)," Materials Chemistry and Physics, vol. 108, no. 2-3, pp. 382-390, 2008.

[8] B. Zhang and F. D. Blum, "Thermogravimetric studies of adsorbed PMMA," Polymer Preprints, vol. 43, no. 1, pp. 484-485, 2002. 
[9] A. Kurt, "Influence of $\mathrm{Alcl}_{3}$ on the optical properties of new synthesized 3-Armed poly(methyl methacrylate) films," Turkish Journal of Chemistry, vol. 34, no. 1, pp. 67-79, 2010.

[10] M. H. Mohmmad, "Study of optical constants of (PMMA) doped with (C14H14N3O6S)," Ibn Al-Haitham Journal for Pure and Applied Science, vol. 23, pp. 1-14, 2010.

[11] M. Chahar, V. Ali, and S. Kumar, "Preparation and spectral investigations of neodymium oxide doped polymethylmethacrylate based laser material," International Journal of Scientific and Research Publications, vol. 2, pp. 2250-3153, 2012.

[12] J. Tauc, Amorphous and Liquid Semiconductors, Pleinum Press, New York, NY, USA, 1974.

[13] A. N. Alias, Z. M. Zabidi, A. M. M. Ali, M. K. Harun, and M. Z. A. Yahya, "Optical characterization and properties of polymeric materials for optoelectronic and photonic applications," International Journal of Applied Science and Technology, vol. 3, no. 5, pp. 11-38, 2013.

[14] H. Zahr El-Deen and A. I. Hafez, "Physics-chemical stability of PVA films doped with $\mathrm{Mn}^{+2}$ ions against weathering conditions," The Arabian Journal for Science and Engineering, vol. 34, no. 1A, pp. 13-26, 2009.

[15] H. M. Zidan, A. Tawansi, and M. Abu-Elnader, "Miscibility, optical and dielectric properties of UV-irradiated poly(vinylacetate)/poly(methylmethacrylate) blends," Physica B: Condensed Matter, vol. 339, no. 2-3, pp. 78-86, 2003.

[16] H. M. Zidan and M. Abu-Elnader, "Structural and optical properties of pure PMMA and metal chloride-doped PMMA films," Physica B, vol. 355, no. 1-4, pp. 308-317, 2005.

[17] S. H. Deshmukh, D. K. Burghate, S. N. Shilaskar, G. N. Chaudhari, and P. T. Deshmukh, "Optical properties of polyaniline doped PVC-PMMA thin films," Indian Journal of Pure and Applied Physics, vol. 46, no. 5, pp. 344-348, 2008.

[18] T. K. Hamad, R. M. Yusop, W. A. Al-Taa'y, B. Abdullah, and E. Yousif, "Laser induced modification of the optical properties of nano-ZnO doped PVC films," International Journal of Polymer Science, vol. 2014, Article ID 787595, 8 pages, 2014.

[19] H. A. Muhammed, S. C. Sami, and F. H. Nadir, "The effect of Iro chromate on the optical properties of PMMA films," Diyala Journal for Pure Science, vol. 6, pp. 161-169, 2010.

[20] W. Al-Taa'Y, M. Abdul Nabi, R. M. Yusop et al., "Effect of nano $\mathrm{ZnO}$ on the optical properties of poly(vinyl chloride) films," International Journal of Polymer Science, vol. 2014, Article ID 697809, 6 pages, 2014.

[21] A. H. Ahmad, A. M. Awatif, and N. Zeid Abdul-Majied, "Doppin effect on optical constants of polymethylmethacrylate (PMMA)," Engineering \& Technology, vol. 25, no. 4, pp. 558-568, 2007.

[22] J. I. Pankove, Optical Processes in Semiconductors, Dover, New York, NY, USA, 1975.

[23] J. F. Eloy, Power Lasers, National School of Physics, John Wiley \& Sons, Grenoble, France, 1984. 

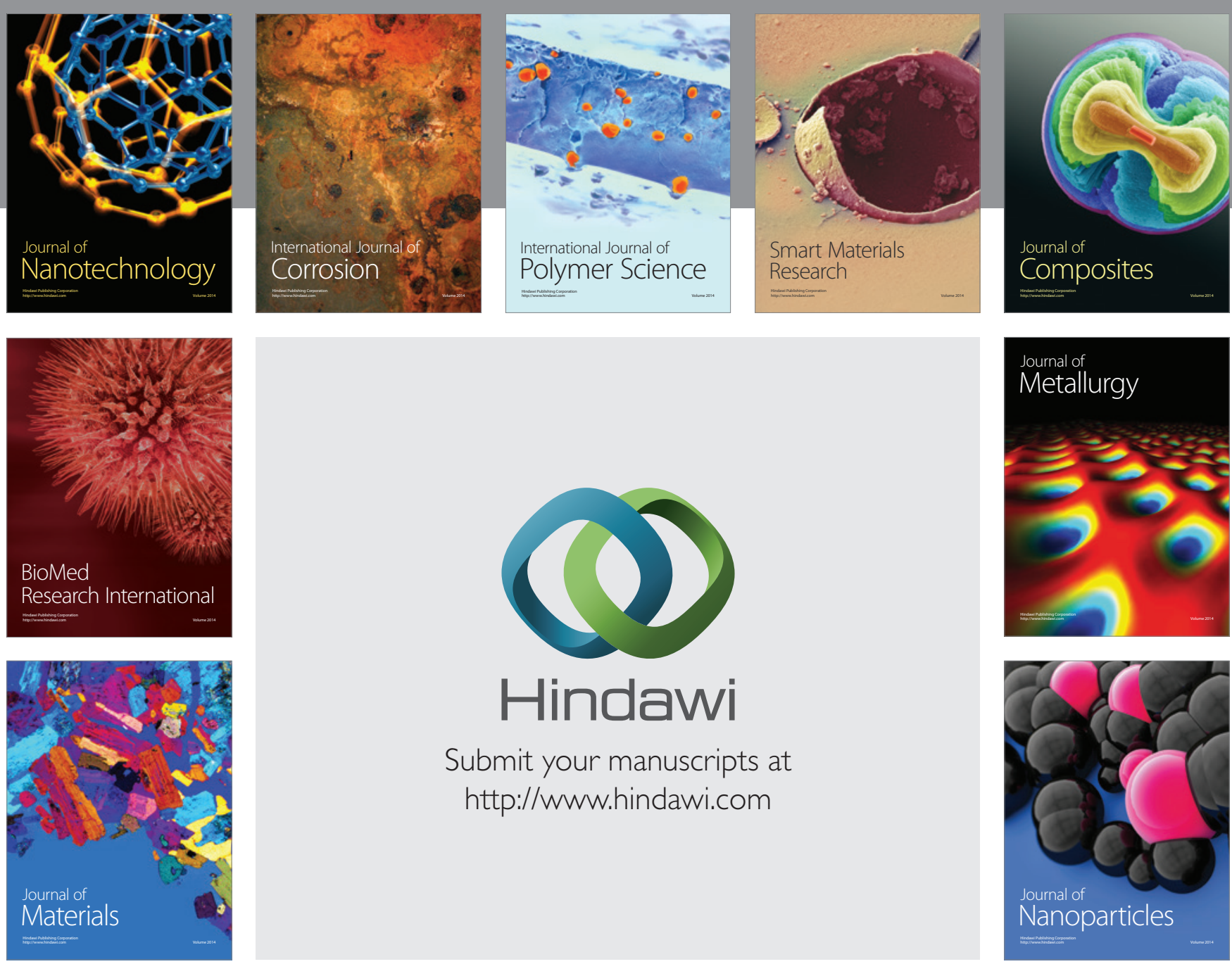

Submit your manuscripts at http://www.hindawi.com
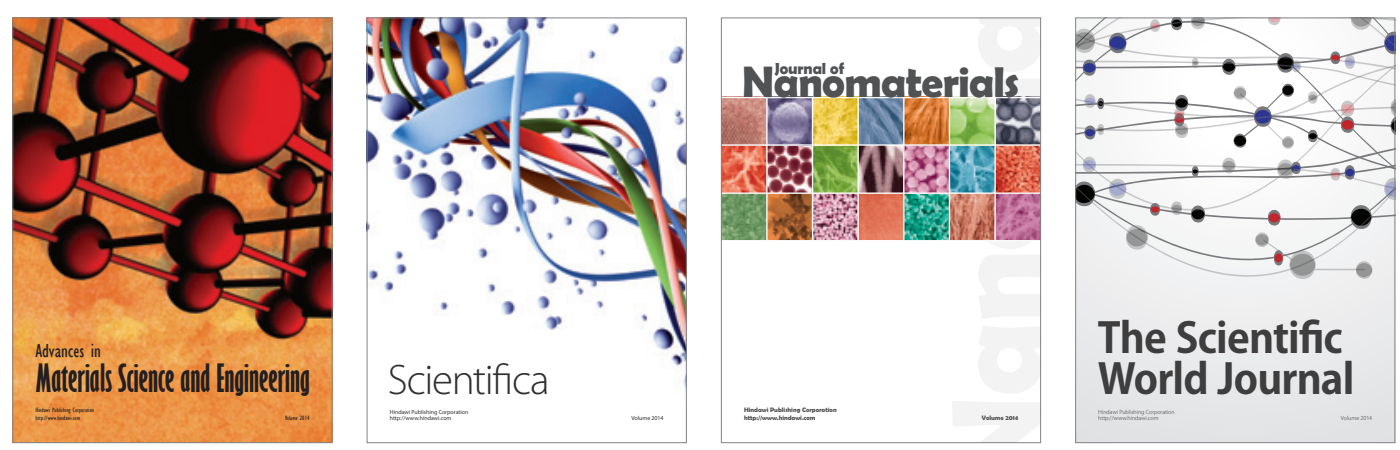

\section{The Scientific World Journal}
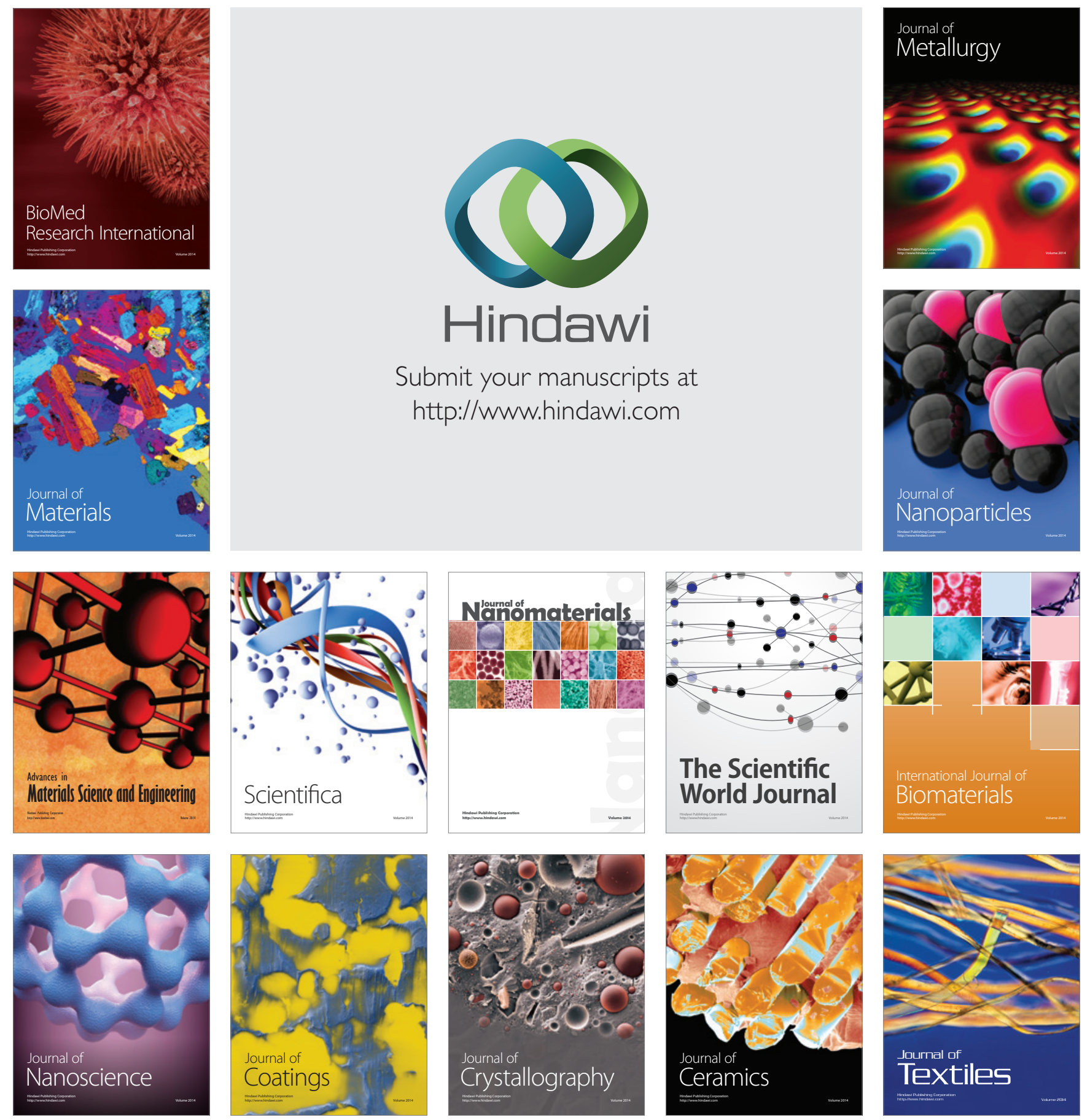